\title{
Epidemiological Profile of Intestinal Parasitic Infections Among Children Living in Koranic Schools: A Cross Sectional Survey
}

\author{
Souleye Lelo ${ }^{1}$, Fatimata Ly $^{2}$, Issac Akhenaton Manga ${ }^{1}$, Cheikh Binetou Fall ${ }^{1}$, Khadime Sylla ${ }^{1}$, \\ Magatte Ndiaye $^{1}$, Doudou Sow ${ }^{1}$, Nick Chenise ${ }^{1}$, Massamba Syll ${ }^{1}$, Roger Clement Tine ${ }^{1}$, \\ Jean Louis Abdourahime Ndiaye ${ }^{1}$, Babacar Faye ${ }^{1}$
}

${ }^{1}$ Departement of Parasitology-Mycology, University Cheikh Anta Diop, Dakar, Sénégal

${ }^{2}$ Service of Dermatology, Hospital Institut Hygiene and Social, Dakar, Sénégal

\section{Email address:}

lelosouleye82@hotmail.com(S. Lelo),lyfaty@yahoo.fr(F. Ly), akhenmanga@yahoo.fr(I. A. Manga),chek2810@yahoo.fr(C. B. Fall), khadimesylla@yahoo.fr (K. Sylla),magou22000@yahoo.fr(M. Ndiaye),doudsow@yahoo.fr(D. Sow), atiganick@yahoo.fr(N.Chenise), syll.massamba@hotmail.fr(M. Syll),roger.tine@ucad.edu.sn(R. C. Tine),jlndiaye@yahoo.com(J. L.A. Ndiaye), bfaye67@yahoo.fr(B.Faye)

\section{To cite this article:}

Souleye Lelo, Fatimata Ly, Issac Akhenaton Manga, Cheikh Binetou Fall, Khadime Sylla, Magatte Ndiaye, Doudou Sow, Nick Chenise, Massamba Syll, Roger Clement Tine, Jean Louis Abdourahime Ndiaye, Babacar Faye. Epidemiological Profile of Intestinal Parasitic Infections Among Children Living in Koranic Schools: A Cross Sectional Survey. International Journal of Infectious Diseases and Therapy. Vol. 4, No. 4, 2019, pp. 67-71. doi: 10.11648/j.ijidt.20190404.13

Received: October 23, 2019; Accepted: November 23, 2019; Published: December 18, 2019

\begin{abstract}
Intestinal parasitic infections causes significant morbidity in worldwide. In Senegal, since 2005 mass deworming campaign has been introduced as a preventive strategy. The main objective of this study was to evaluate the prevalence of intestinal parasitic infection among children living in Koranic teaching Schools in Senegal. A cross-sectional study was conducted from January to May 2018. Koranic schools were selected using simple random sampling and data on sociodemographic characteristicsand prevalence were collected. Stool samples were collected and treated accordingly. Descriptive analysis was performed using Stata software. Significance level was set at 5\%. A total of 463 children were recruited in this study. The mean age of study population was $10.93 \pm 2.4$. The overall prevalence of intestinal parasites was $22.68 \%$. Polyparasitism was detected in $20 \%$ of students. Students infected with single, double and triple parasites were $80 \%, 19.05 \%$ and $0.95 \%$, respectively. The most common parasites were Entomoba coli cyst $(33.33 \%)$, followed by Ascaris lumbricoides (32.38\%), Giardia cyst (9.52\%), Trichirus Trichiura (3.81\%) and Schistosoma mansoni 0.95\%. Intestinal parasites were more common in peri-urban areas $(66.31 \%)$. Intestinal parasitic infection has been found to be very common in Koranic school children. Therefore, health education, improvement of learning and living conditions, and student deworming are essential.
\end{abstract}

Keywords: Helminths, Protozoans, Koranic Schools, Dakar

\section{Introduction}

Intestinal parasitic infections (IPI) are still public health problems in many communities, particularly among children living in developing countries. More than 2 billion people in worldwide are estimated to be infected with IPI and more than half of the world's population are at risk of infection [1, 2]. In Sub-Saharan countries, 866 million individuals are infected by Soil-Transmitted Helminth (STH), with the majority of these infections occurring among school children. The World Health Organisation (WHO) estimates that 450 million are ill $[3,4]$. In addition to the morbidity and mortality, infections with intestinal parasites have been associated with stunting, underweight, physical weakness and low educational performance in school children [5.6]. The control strategies of STH in many endemic countries usually involve mass drug administration (MDA) programmes with single oral dose of mebendazole or Albendazole periodically administered to pre-school and school children [7-9]. 
In order to control the morbidity associated with intestinal parasitic diseases in pre-school and school children, the Senegal Ministry of Health adopted the WHO recommendation (Mass deworming programme with Mebendazole). Recent studies have found protozoa to be the most prevalent parasitic infection compared to helminths infection in Senegal [10-12].

This strategy has significantly reduced the morbidity related to intestinal parasitic infection. However limited data are available on STH among children living daara with deforable conditions (promiscuity, malnourish, lack of hygiene, street children); therefore, it become important to evaluate the prevalence of the intestinal parasitic infection among these children.

The objective of this study was to evaluate the prevalence of intestinal parasitic infection among children living in Koranic teaching Schools in Senegal.

\section{Patients and Methods}

\subsection{Study Area}

This study was conducted in a health districts located in the Dakar region, after identifying the Koranic schools of the district.

\subsection{Study Design and Population}

A cross-sectional study was conducted from January to Octobre 2018 in selected Koranic schools and all children living in the said schools were included in this study. A simple random sampling method was performed prior to the inclusion of Koranic schools. Informed consent of legal representatives of children was required prior the inclusion in the study.

\subsection{Study Procedure}

A code was given to every child after his/her legal representative's informed consent. All the children were examined by a physician prior to a biological assessment which included stool samples. The children were interviewed directly on the symptoms as well as sociodemographic characteristics using a standard questionnaire. Data obtained from physical examination and interviews of the legal representatives were entered on a case report form (CRF).

\subsection{Biological Assessment}

The children were given a clearly labelled, wide-mouth and screw-capped containers and were instructed to bring their early morning stool samples the next day. The collected samples were transported (within 5 hours of collection) in suitable cool boxes at temperature between 4 and $6^{\circ} \mathrm{C}$ for examination at the Department of Parasitology of the Faculty of Medicine, University of Dakar. Stool samples were examined macroscopically for colour, consistency, presence of blood, mucus, pus and large worms. A portion each of the stool samples was processed for direct examination using light microscopy to detect cysts, trophozoite, eggs and larvae. The remaining parts of stool samples were examined using a modified Ritchie technique.

\subsection{Data Analysis}

Data from questionnaires was entered into a Microsoft Access database using Excel software. Data cleaning procedures were performed before importing data for analysis into Stata IC 12 . Descriptive analysis was performed. For quantitative variables, means and standard deviation were used to describe study population. ANNOVA test or Student $t$ test after checking the conditions of application were used for inter-group comparison. A description in terms of frequency with $95 \%$ confidence interval was used for descriptive variables. Significance level of different tests was set at 5\% two sides.

\section{Results}

\subsection{Socio Demographic Characteristics of Study Population}

A total of 463 participants were included in this study. The mean of the study participant was $10.9 \pm 2$. Study population was mainly represented by children between 5-10 years old (69.52\%). Children under 5 years and those aged over represent $28.57 \%$ and $13.61 \%$ respectively. The sex ratio was 8.3. (Table 1).

Table 1. Characteristics of study participants.

\begin{tabular}{llll}
\hline Variable & Frequency $(\mathbf{n}=\mathbf{4 6 3})$ & Percentage $(\mathbf{\%})$ & $\mathbf{9 5 \%}$ IC \\
\hline Age group & & & \\
$<5$ years & 128 & 28,57 & $23,2-32,8$ \\
[5- 10$]$ & 272 & 69,52 & $51,2-76,8$ \\
$>10$ years & 63 & 13,61 & $10,2-17,8$ \\
Sex & & & \\
Female & 49 & 10,58 & $07,8-13,8$ \\
Male & 414 & 89,42 & $43,9-90,3$ \\
\hline
\end{tabular}

\subsection{Prevalence and Distribution of Intestinal Parasitic Infections}

Overall, $22.7 \%(105 / 463)$ of the children were found infected with at least one intestinal parasite species. Intestinal parasites were mainly represented by protozoan parasites (44. $76 \%$ ) and Helminth parasites (41.9\%). Association between protozan and helminth parasites was observed in $13.33 \%$ cases as shown in (Table 2).

Table 2. Prevalence of intestinal parasitic infection.

\begin{tabular}{llll}
\hline Variable & Frequency & Pourcentage & IC 95 \\
\hline Result & & & \\
Negatif & 358 & 77,3 & $69,5-85,7$ \\
Positif & 105 & 22,7 & $18,5-27,5$ \\
Parasite & & & \\
helminth & 44 & 41,9 & $30.4-56.3$ \\
Protozoan & 47 & 44,76 & $32.9-59.5$ \\
Protozoan and Helminth & 14 & 13,33 & $32.9-59.5$ \\
Association & & & \\
yes & 21 & 20 & $12.4-30.6$ \\
no & 84 & 80 & $65.3-95.6$ \\
\hline
\end{tabular}


The main species were Entamoeba coli cyst (33.33\%), Ascaris lumbricoides (32.38\%), Giardia cyst (9.52\%), Trichirus trichiura $(3.81 \%)$ and Schistosoma mansoni $(0.95 \%)$. The main associations were Ascaris lumbricoides + Entomoba coli $10.48 \%$, Ascaris lumbricoides + Trichirus trichiura, Ascaris lumbricoides + Giardia cyst, Entomoba coli cyst + Giardia cyst and (v) Entomoba coli cyst + Trichirus trichiura. However, triple infection was noted with association between Ascaris lumbricoides + Trichirus Trichiura + Entomoba coli cyst (0.95\%). (Table 3$)$.

Table 3. Intestinal parasite and possible risk factors.

\begin{tabular}{|c|c|c|c|}
\hline Variable & Frequency & Percentage 95\% IC & Pvalue \\
\hline \multicolumn{4}{|c|}{ Age group (years) } \\
\hline$<5$ & 30 & $23,4(15,8-33,5)$ & $<10^{-3}$ \\
\hline$[5-10]$ & 73 & $26,8(21,03-33,7)$ & \\
\hline$>10$ & 02 & $3,17(0,38-11,47)$ & \\
\hline \multicolumn{4}{|l|}{ Gender } \\
\hline Female & 11 & $22,5(11,2-40,2)$ & 0,96 \\
\hline Male & 94 & $22.7(18.3-27.8)$ & \\
\hline \multicolumn{4}{|l|}{ Zone } \\
\hline Urban & 32 & $23,4(15,8-33,5)$ & \\
\hline Peri-urban & 73 & $23,8(18,6-29,8)$ & 0,43 \\
\hline
\end{tabular}

\subsection{Intestinal Parasite and Possible Risk Factors}

The results of this study showed that intestinal parasitic infection increased with age. The prevalence was higher among children aged between 5 and 10 years old (26.8\%). In children under 5 years old and those aged over 10 years, the prevalence was respectively $23,4 \%$ and $3.17 \%$. The difference between age group was significative $\left(\mathrm{p}<10^{-3}\right)$. Regarding the gender, the prevalence was higher among male participants $(22.7 \%)$ compared to female participants $(22.5 \%)$ but the difference was not significant $(p=0.96)$. Regarding the location of the Koranic schools, a significant difference was not observed between school children living in urban area $(23.4 \%)$ and those living in peri-urban area $(23.8 \%)(\mathrm{p}=0.43)$.

\section{Discussion}

As part of a long-term goal of eliminating STH as public health problem by 2020 , WHO recommended MDA with single oral dose of mebendazole or albendazole periodically administered to pre-school and school-age children [7, 8]. This strategy is currently implemented in many countries including Senegal.

The study showed an overall prevalence of $22.7 \%$ of intestinal parasites infection. Protozoan parasites were more frequent $(44.76 \%)$ than helminth parasites were $(41.9 \%)$. Association between protozoan and helminth parasites was found in $19.02 \%$ cases. These results are in line with an earlier study carried out in rural area (Keur Soce) in 2013 by Tine and al who showed $26.2 \%$ of prevalence for intestinal parasites with a predominance of protozoan parasites. [12]

Compared to urban area in Senegal, similar results [Sylla and al in 2013] showed a prevalence $26.8 \%$. [11] while Ndiaye and al in 2013 reported a $20.3 \%$ prevalence. [13].
Contrary to previous studies conducted in Senegal, helminth infections have become rare while protozoan infections are more common. Indeed, previous studies demonstrated a prevalence of helminth infections of $42-56 \%$ [14].

Our results are in line with this study because children living in Koranic Teaching Schools in Senegal do not properly receive single oral dose of mebendazole or albendazole periodically.

Similar results are found in some African countries, i.e. Kenya (25.6\%) [15], and Ethiopia (26.2\%) [16]. Some differences of prevalence are found in Algeria (19.6\%) with a high rate of protozoan $(95.7 \%)$ compared to helminth (4.7\%) [17]. In contrast, studies conducted in Senegal show a low prevalence of intestinal parasitic infection compared to those in Ivory Coast and Burkina Faso which stand at $68.2 \%$ and $75.8 \%$ respectively. [18-19].

Our results found that the prevalence of intestinal parasitic was higher among male participants than female participant but the difference was not statistically significant. The same results were observed in Yemen [20]. In contrast in Kenya our studies reported that the prevalence was higher in female participants $(42.5 \%)$ compared to male participants [21]. The results of this study found that intestinal parasitic infection is more observed in children between 5-10 years of age compared to other age groups. The prevalence of helminthic infections is higher compared to the results of several studies in Senegal showing a low prevalence of helminthic infections in other rural areas [12] and other sub-Saharan countries [22]. Several years after the implementation of mass deworming campaigns, children living in Koranic Schools still have parasites on them simply because when the medical team visits schools they are out in the streets begging for alms.

\section{Conclusion}

The prevalence of intestinal parasitic infestations in koranic Schools is high, which is a public health problem. The most common parasite identified was Entamoeba coli cyst and the least commonly identified parasite was Schistosoma mansoni. This study revealed a balance with helminthic infections while protozoan infections among children living in koranic Schools may require revision of the current deworming policy programme. However, extensive data at the national level are needed to support modification of strategy.

\section{Acknowledgements}

We would like to acknowlegdge CEA-SAMEF (Centre d'Excellence Africain de la Santé Mére -Enfant). The project /funding number P 00017/2017.

\section{Funding}

This study was funded by CEA-SAMEF (centre d'excellence Africain de la santé Mére -enfant). 


\section{Ethical Approval and Consent for Participation}

This study was conducted according to the declaration of Helsinki and existing national legal and regulatory requirements. The protocol was reviewed and approved by the Senegalese Ethics at the university. Approval number 0258/2017/CER/UCAD. Informed consent of parent or legal representative was required prior the participation to the study. To respect the confidentiality, an identification code was given to each participant.

\section{Availability of Data and Material}

All data generated or analysed during this study are included in this manuscript and are available from the corresponding author on reasonable request.

\section{Competing Interests}

The authors declare that they have no competing interest

\section{Author Contributions}

FL, BF, SL conceived and designed the study. FL, BF, SL, NC supervised the data collection. KS analysed the data. SL wrote the first draft of the manuscript. All authors read and approved the final manuscript.

\section{References}

[1] Hotez PJ, Fenwick A, Savioli L, Molyneux DH (2009) Rescuing the bottom billion through control of neglected tropical diseases. Lancet 373: 1570-1575.

[2] WHO (2002) Prevention and control of intestinal parasitic infections: prevention and control of schistosomiasis and soiltranmitted helminthiasis: report of WHO expert committee. WHO Tech Rep Ser 912: 1-57.

[3] Pullan RI, Smith JL, Jasrasaria R, Brooker SJ (2014). Global numbers of infection and disease burden of soil transmitted helminth infections in 2010. Parasit. Vectors 7: 37.

[4] Alum A, Rubino JR, Ijaz MK (2010) The global war against intestinal parasites-should we use a holistic approach. Int Infect Dis 14: 732-738.

[5] Okyay P, Ertug S, Berna G, Ozlem O, Erdal B (2004) Intestinal parasites prevalence and related factors in school children, a western city sample-turkey. BMC Public Health 4: 64.

[6] Amuta E, Olusi T, Houmsou R (2013) Relationship of intestinal parasitic infections and malnutrition among school children in Makurdi, Benue State, Nigeria. Internet J Epidemiol 7: 20-24.

[7] Levecke B, Montresor A, Albonico M, Ame SM, Behnnke JM, Bethony JM, Noumedem CD, Engels D, Guillard B, Kotze AC, Krolewiecki AJ, McCarthy JS, Mekonnen Z, Periago MV, Sopheak H, Tchuem-Tchuenté LA, Duong TT,
Huong NT, Zeynudin A, Vercruysse J (2014). Assessment of anthelmintic efficacy of mebendazole in school children in six countries where soil-transmitted helminths are endemic. Plos Negl. Trop. Dis. 8: e3204.

[8] Gabrielli AF, Montresor A, Chitsulo L, Engels D, Savioli L (2011). Preventive chemotherapy in human helminthiasis: theoretical and operational aspects. Trans. R. Soc. Trop. Med Hyg. 105: 683-693.

[9] Word Health Organization (WHO) (2012). Accelerating work to overcome the global impact of neglected tropical diseases: a roadmap for implementation. Geneva: WHO.

[10] World Health Organisation (2004) Schistosomiase et geohelminthiases: prevention et lutte: Rapport d'un comité d'expert de l'OMS. Serie De Rep Tech 1: 5.

[11] K Sylla, RCK Tine, D Sow, T Dieng, B Faye, et al. (2013) Epidemiological aspects of intestinal parasitic infection diagnosed in Parasitology and Mycology laboratory of Fann hospital, Dakar. Med Afr Noire 60: 339-346.

[12] Tine RC, Faye B Ndour CT, Sylla K, Sow D et al. (2013) Parasitic Infections among Children under Five Years in Senegal: Prevalence and effects on Anaemia and nutritional Status. ISRN Parasitol 272701: 6.

[13] Ndiaye D, Ndiaye M, Gueye PAL, Badiane A, Fall ID, et al. (2013) Intestinal helminthiasis diagnosed in Dakar, Senegal. Med Sante Trop 23: 35-38.

[14] Faye B, Ndiaye JL, Tine RC, Lo AC, Gaye O (2008). Interaction between malaria and intestinal helminthiasis in Senegal: influence of the carriage of intestinal parasites on the intensity of the malaria infection. Bull. Soc. Pathol. Exot. 101: 391-394.

[15] MBea CK, Nokes DJ, Mulinge E, Nyambura J, Waruru A, et al (2013) I ntestinal parasitic infections in Children presenting with diarrhoea in outpatient and inpatient settings in an informal settlement of Nairobi, Kenya. BMC Infect Dis 13: 243.

[16] Begna Tulu, Solomon Taye, Eden Amsalum (2014) Prevalence and its associated risk factors of intestinal parasitic infections among Yadot primary school children of South Eastern Ethiopia: a cross-sectional study. BMC Res Notes 7: 848 .

[17] Benouis A, Bekkouche Z, Benmansour Z (2013) Etude epidemiologique des parasitosis intestinalis humaines au niveau du CHU d'oran Algerie. Inter J Innov App Studies 2: 613-620.

[18] Houphouet Felix Yapi, H Ahiboh, D Monnet, AE Yapo (2015) Parasites intestinaux, profil hematologique et statut anthropometrique de l'enfant scolarisé en cote d'Ivoire. Cahiers Santé 15: 17-21.

[19] Savadogo B, Bengaly MD, Zongo D, Zeba AN, Poda J, et al. (2015) Anémie et parasitosis (intestinalis et urinaires) chez les enfants d'age scolaire au Burkina Faso: cas des écoles de Yamtenga, Daguilma et Koubri. Int J Biol Chem Sci 9: 14591469.

[20] Al-Mekhlafi AM, Abdul-Ghani R, Al-Eryani SM, Saif-Ali R, Mahdy MA (2016) School-based prevalent of intestinal parasitic infections and associated risk factors in rural communities of Sana'a, Yemen. Acta tropica 163: 135-141. 
[21] Kavili DM, Simbauni JA, Gicheru MM, Mungiria JN (2016) Prevalence and risk factors of Entomoeba histolytica amongst Children Attending Primary Schools in Kyuso Zone, Kyuso District, Kitui County, Kenya. JALSI 7: 1-12.
[22] Moser W, Labhardt ND, Cheleboi M, Muhairwe J, Keiser J (2017). Unexpected low soil-transmitted helminth prevalence in the Butha-Buthe district in Lesotho, results from a crosssectional survey. Parasit. Vectors 10: 72. 